\title{
Saúde mental e trabalho: descrição da produção acadêmica no contexto da pós-graduação brasileira
}

\author{
Adélia Augusta Souto de Oliveira ${ }^{1}$ e Juliano Almeida Bastos ${ }^{2}$ \\ Universidade Federal de Alagoas (Maceió, AL)
}

\begin{abstract}
Este estudo descreve a produção acadêmica da área de Saúde mental e trabalho na pós-graduação brasileira. A partir de uma perspectiva qualitativa, realizou-se uma pesquisa de tipo bibliográfica com os documentos disponíveis nos bancos de teses e dissertações da CAPES e da BVS-Psi. Os resultados indicam que a área tem sido estudada eminentemente em nível de mestrado; $84 \%$ são dissertações e 16\% são teses. Os primeiros documentos datam de 1989. A partir do ano 2000, a produção cresceu consideravelmente: $88 \%$ do material data deste período. Predominam estudos ligados à Psicologia: 56\% dos documentos. A região Sudeste concentra 46\% do total; São Paulo responde por 30\%, indicando uma grande concentração de estudos nessa região do país. Identifica-se ainda 49 instituições que apresentam produção de estudos, sendo USP, UFRJ, UFRGS, UNB e UFMG as que mais produzem. Conclui-se que a área de Saúde mental e trabalho surgiu do contexto socio-histórico em que se desenvolveu o campo da Saúde do trabalhador no Brasil. A produção proveniente em maior proporção de universidades públicas parece indicar um compromisso ético e político destas instituições em responder aos problemas sociais que demandam investigação científica.
\end{abstract}

Palavras-chave: Saúde mental e trabalho; pós-graduação brasileira; descrição.

Mental health and work: description of the academic production in the Brazilian postgraduate

This study describes the academic production of the Mental health and work area in the Brazilian postgraduate. From a qualitative perspective, a biographic research was done with documents available on bank theses and dissertations from CAPES and BVS-PSI. The results indicate that the area has been studied essentially at Master's level; $84 \%$ of them are dissertations and $16 \%$ are theses. The first documents dates back to 1989. Since 2000 the production increased considerably: $88 \%$ of the material is from that period. $56 \%$ of these documents are related to Psychology: The Southeast region concentrates $46 \%$ of the total and São Paulo responds to 30\%, indicating a large concentration of studies in this area of the country. It also identifies that 49 institutions presents study productions, and USP, UFRJ, UFRGS, UNB and UFMG are the most contributors. According to all this, we can conclude that the area of Mental health and work emerges from the socio-historical context in which developed the field of the workers' Health in Brazil. The production in higher number from public universities seems to indicate an ethical and political commitment of these institutions in response to social problems that require scientific research.

Keywords: Mental health and work; Brazilian postgraduate; description.

\section{Introdução}

A área de Saúde mental e trabalho considera a influência direta do trabalho na constituição da subjetividade e, nesse sentido, propõe o estudo de aspectos relacionados ao trabalho nos processos de adoecimento psíquico (Araújo, 2011). Compreende, pois, a análise articulada das categorias saúde mental e trabalho e sua repercussão na saúde dos trabalhadores.

Este estudo tem o objetivo de investigar como essa área do conhecimento tem se desenvolvido no contexto da pós-graduação brasileira, e para isso descreve a produção acadêmica disponível nos bancos de teses e dissertações da Coordenação de Aperfeiçoamento de Pessoal de Nível Superior (CAPES) e da Biblioteca Virtual em Saúde-Psicologia (BVS-Psi).

Uma breve análise do panorama do mundo do trabalho na contemporaneidade apresenta uma indicação acerca dos motivos que favoreceram a emergência e consolidação dessa área do conhecimento. Borsoi (2007) aponta que, se no século XIX a preocupação dos trabalhadores frente às condições de trabalho estava relacionada à própria sobrevivência, no século XX, com $\mathrm{o}$

1 Doutora em Psicologia Social (PUC-SP).

2 Mestre em Psicologia (UFAL). 
acentuado processo de industrialização e a adoção de novas formas de gestão do processo produtivo (sobretudo no final dos anos 60 e início dos anos 70), observa-se uma exigência cada vez maior da capacidade física e, sobretudo, psíquica dos trabalhadores.

No cenário brasileiro, as transformações no mundo do trabalho ocorreram em maior proporção na década de 80 , através da inserção de novas tecnologias e das alterações nas relações e formas de organização do trabalho (Antunes, 2011; Antunes \& Silva, 2010; Navarro \& Padilha, 2009). Nessa conjuntura, observa-se repercussões intensas na saúde dos trabalhadores, sendo uma das consequências prementes o aumento das exigências mentais de ordem cognitiva, emocional e psicossocial (Glima \& Rocha, 2010; Sennett, 2003).

A área de Saúde mental e trabalho se insere, portanto, no campo da Saúde do trabalhador; por isso faz-se necessário abordar, ainda que de forma sumária, como este campo se constituiu no Brasil e possibilitou o desenvolvimento da área em questão. Tal incursão favorece a compreensão acerca das condições socio-históricas em que esse desenvolvimento se deu e, mais que isso, as implicações desse contexto para a conformação da área.

As primeiras sistematizações referentes à Saúde do trabalhador no Brasil surgem nos anos de 1950 e 1960, período que compreende, respectivamente, a segunda grande onda de industrialização no país e a crise política que culminou no golpe militar e na adoção de políticas totalitárias, inclusive na questão do trabalho (Frias Junior, 1999).

O final dos anos de 1970 pode ser apontado como marco histórico para a consolidação do campo da Saúde do trabalhador no Brasil. Campo que se constitui ancorado em múltiplas dimensões: técnica, política e ética; marcadamente caracterizado pelo compromisso pela mudança na situação da saúde dos trabalhadores do país e pela participação dos movimentos sociais nesse processo (Lacaz, 1996, 1997, 2007; Mendes \& Dias, 1991).

Enquanto campo de conhecimento, a Saúde do trabalhador pode ser compreendida como "um corpo de práticas teóricas interdisciplinares - técnicas, sociais, humanas - e institucionais, desenvolvidas por diversos atores situados em lugares sociais distintos e informados por uma perspectiva comum." (Minayo-Gomez \& Thedim-Costa, 1997, p. 25).

Com o processo de redemocratização do país, em meados dos anos 80, as questões da Saúde do trabalhador inserem-se no âmbito da Saúde pública, o que possibilitou a estruturação de uma política pública de Saúde do trabalhador, com a criação de dispositivos e a sistematização de ações referendadas pelos pressupostos da Saúde coletiva (Minayo-Gomez, 2011).

A partir da abordagem da Saúde coletiva, a categoria trabalho associa-se ao conceito de processos de trabalho, o que amplia o foco de análise para além dos agentes tradicionais fundamentados na observação do ambiente e das condições de trabalho. Torna-se, então, possível a adoção de uma perspectiva de análise que considera a relação entre trabalho e subjetividade (Minayo-Gomez \& Thedim-Costa, 1997; Sato, Lacaz \& Bernardo, 2006).

A área denominada Saúde mental e trabalho surge então dessa perspectiva onde a subjetividade é analisada em articulação com o trabalho. Sato \& Bernardo (2005) e Seligmann-Silva (2006, 2011) apontam que desde os anos de 1920 essa área vem se fortalecendo enquanto campo de investigação e produção científica ao propor o estudo da interface entre saúde mental e trabalho.

Nessa perspectiva, compreende-se saúde mental como um campo complexo que busca superar os modelos paradigmáticos reducionistas da medicina clássica e que passa a considerar a primazia das condições e possibilidades da existência humana na constituição da subjetividade (Amarante, 2007; Codo, 2004; Delgalarrondo, 2008; Lima, 2006).

O trabalho, por sua vez, é tomado enquanto elemento que assume uma centralidade na composição dos modos de vida nas diversas formas de organização social. Compreendido enquanto elemento constituinte da subjetividade, ação humana de intervenção e transformação sobre a natureza, o trabalho reverte-se em ação de intervenção e transformação na cultura, na relação 
com o outro e, consequentemente, na autotransformação de si (Antunes, 2004, 2011; Arendt, 2007; Clot, 2007; Lukács, 2012; Vieira, Barros \& Lima, 2007).

No Brasil, ao longo das últimas três décadas, o estudo da relação entre saúde mental e trabalho ganhou força, e tem se tornado um interesse crescente de pesquisadores que apresentam uma produção acadêmica caracterizada, eminentemente, pela diversidade de concepções teóricas e metodológicas em diferentes perspectivas. Essa dinâmica tem consolidado uma profícua e abrangente área de conhecimento (Araújo, 2011; Codo, Soratto \& Vasques-Meneses, 2004; Lima, 2013).

Dois importantes aspectos são também apontados por Jacques (2003) para compreenderse o desenvolvimento das pesquisas acerca da relação entre saúde mental e trabalho nas últimas décadas no Brasil, bem como o interesse da Psicologia pela área: o aumento do número de transtornos mentais e de comportamento associados ao trabalho, apontados pela Organização Mundial de Saúde (OMS) e pelo Instituto Nacional de Seguridade Social (INSS), e a realização, na década de 80, da VIII Conferência Nacional de Saúde (VIII CNS) e da I Conferência Nacional de Saúde do Trabalhador (I CNST), cujas mudanças propostas favoreceram a aproximação da Psicologia no campo da Saúde do trabalhador.

Na introdução do livro Saúde Mental e Trabalho - leituras (Jacques \& Codo, 2002, p. 17), justifica-se a publicação apontando uma urgência: "Existe uma lacuna preocupante na formação da graduação e pós-graduação em Ciências Humanas e Sociais no mundo, e também no Brasil”. Na sequência, é apresentada uma caracterização das intensas mudanças ocorridas no mundo do trabalho, chamando-se a atenção para a repercussão dessas mudanças na saúde mental dos trabalhadores. Paralelamente é pontuado o problema da falta de informações precisas no Brasil acerca da Saúde mental e trabalho, quando em comparação com outros países.

Passados mais de 10 anos da urgência apontada por estes autores, investigou-se nesse estudo o desenvolvimento da área da Saúde mental e trabalho no Brasil a partir da produção acadêmica teses e dissertações - sobre a temática. Partindo de uma perspectiva qualitativa de pesquisa (Flick, 2009), as informações coletadas foram integradas, produzindo uma descrição que reflete o estado atual dessa área do conhecimento no contexto proposto.

\section{Método}

Foi adotada uma perspectiva qualitativa de pesquisa bibliográfica do tipo descritiva, utilizando-se documentos (Flick, 2009). Foram definidas quatro fases para o desenvolvimento deste estudo: Exploração, Refinamento, Cruzamento e Descrição. As três primeiras compreendem os procedimentos adotados para a composição da amostra, e última diz respeito aos resultados alcançados e apresenta material para as discussões realizadas.

\section{Amostra}

Os documentos para a constituição da amostra foram localizados em dois bancos de dados: 0 banco de teses e dissertações disponível no sítio virtual da CAPES e o banco de teses e dissertações da BVS-Psi. O primeiro foi escolhido pela relevância que esta coordenação possui no contexto da pós-graduação no Brasil, em especial no que se refere à promoção e divulgação da produção científica nas mais diversas áreas do conhecimento. A opção pela BVS-Psi justifica-se por se tratar de uma biblioteca virtual especializada no âmbito da Saúde e da Psicologia. 


\section{Fase de Exploração}

Nessa fase definiram-se os descritores para a busca do material nos dois bancos de dados. Foram inicialmente determinados quatro descritores: 1 - saúde mental e trabalho; 2 - sofrimento psíquico e trabalho; 3 - psicopatologia e trabalho e 4 - psicodinâmica do trabalho; eleitos por estarem presentes na produção já considerada clássica desta área do conhecimento no Brasil (Codo, Soratto \& Vasques-Menezes, 2004).

A leitura flutuante (Bardin, 2002) dos primeiros achados conduziu a outros seis descritores: 5 - transtorno mental e trabalho; 6 - doença mental e trabalho; 7 - loucura no trabalho; 8 sofrimento mental no trabalho; 9 - transtorno psíquico no trabalho e, finalmente, 10 - estresse mental e trabalho. Esses seis novos descritores foram considerados variações semânticas dos quatro iniciais. Além dessa variação adotou-se uma variação sintática dentro de cada descritor, compondo para cada um, três construções distintas. $\mathrm{O}$ descritor 1 - saúde mental e trabalho, por exemplo, apresenta as variações: saúde mental no trabalho e saúde mental do trabalho. Os demais descritores seguiram o mesmo padrão.

Com a configuração desses 30 descritores consolidou-se o instrumento de acesso inicial ao material para a constituição da amostra. Para garantir a precisão na apreensão do material, foram utilizadas ferramentas de filtro de busca disponíveis nos dois bancos de dados. Essas ferramentas possibilitam a seleção de documentos que apresentem conexão entre as palavras como expressas no descritor, no caso da BVS-Psi, ou a expressão tal qual apresentada, no caso do banco da CAPES. Acionar essas ferramentas implica selecionar documentos cujo conteúdo apresente uma aproximação com a área pesquisada, seja de forma direta ou indireta, a partir da presença das expressões utilizadas como descritores de busca.

Nos meses de maio e junho de 2013, foi realizado o processo de identificação das teses e dissertações nos dois bancos de dados. Nessa primeira fase foram localizados 1.425 documentos, sendo 361 provenientes do banco da CAPES e 1.064 da BVS-Psi.

O descritor 1 - saúde mental e trabalho apresenta maior eficiência na captura dos documentos nos bancos de teses e dissertações consultados. Ao considerar as variações sintáticas deste, verifica-se que responde por $83 \%$ do material coletado no banco da CAPES, e por 39\% do material coletado na BVS-Psi. Essa eficiência pode ser considerada como um indicativo da representatividade desse descritor no conjunto da produção acadêmica da temática em questão.

\section{Fase de Refinamento}

Finalizada a fase de Exploração, procedeu-se o exame dos dados a partir da leitura do título, do resumo e das palavras-chave de todas as teses e dissertações localizadas. A execução desses três procedimentos teve como objetivo verificar se cada material coletado, na fase de Exploração, possuía relação com a área da Saúde mental e trabalho.

Foram, portanto, lidos os títulos, resumos e palavras-chave dos 1.425 trabalhos coletados. A realização desse procedimento trouxe novos resultados, como se pode verificar no Quadro 2, que apresenta uma comparação entre a quantidade de documentos coletados na fase de Exploração e a quantidade de documentos identificados com a área da Saúde mental e trabalho na fase de Refinamento, por descritor, nos bancos de teses e dissertações da CAPES e da BVS-Psi.

O resultado alcançado com a fase de Refinamento corresponde a 44\% do material coletado na fase de Exploração. Isso significa que mais da metade do material coletado na primeira fase, $56 \%$, não apresentava relação com a área da Saúde mental e trabalho, e por isso foi eliminado da 
amostra, que passa a ser composta por 624 documentos; 291 advindos do banco da CAPES e 333 da BVS-Psi. O descritor 1 - saúde mental e trabalho permanece como o mais eficiente na captura das teses e dissertações nos dois bancos de dados acessados.

A fase de Refinamento também resulta na eliminação do descritor de número 5 em suas três variações sintáticas, pois, após o procedimento realizado nessa fase, foram eliminados todos os documentos coletados por esse descritor, ficando o mesmo sem função para análises posteriores.

Quadro 1. Resultados obtidos com a fase de Exploração

\begin{tabular}{|c|c|c|c|c|}
\hline \multicolumn{5}{|c|}{ Fase 1 - Exploração } \\
\hline & & Descritores & Quant. Capes & Quant. Bvs-psi \\
\hline \multirow{3}{*}{1} & 1.1 & Saúde mental e trabalho & 144 & 142 \\
\hline & 1.2 & Saúde mental no trabalho & 13 & 127 \\
\hline & 1.3 & Saúde mental do trabalho & 144 & 141 \\
\hline \multirow{3}{*}{2} & 2.1 & Sofrimento psíquico e trabalho & 1 & 47 \\
\hline & 2.2 & Sofrimento psíquico no trabalho & 18 & 44 \\
\hline & 2.3 & Sofrimento psíquico do trabalho & 0 & 46 \\
\hline \multirow{3}{*}{3} & 3.1 & Psicopatologia e trabalho & 0 & 42 \\
\hline & 3.2 & Psicopatologia no trabalho & 0 & 41 \\
\hline & 3.3 & Psicopatologia do trabalho & 10 & 33 \\
\hline \multirow{3}{*}{4} & 4.1 & Psicodinâmica e trabalho & 0 & 46 \\
\hline & 4.2 & Psicodinâmica no trabalho & 0 & 46 \\
\hline & 4.3 & Psicodinâmica do trabalho & 10 & 41 \\
\hline \multirow{3}{*}{5} & 5.1 & Transtorno mental e trabalho & 0 & 9 \\
\hline & 5.2 & Transtorno mental no trabalho & 0 & 8 \\
\hline & 5.3 & Transtorno mental do trabalho & 0 & 9 \\
\hline \multirow{3}{*}{6} & 6.1 & Doença mental e trabalho & 0 & 21 \\
\hline & 6.2 & Doença mental no trabalho & 1 & 18 \\
\hline & 6.3 & Doença mental do trabalho & 0 & 21 \\
\hline \multirow{3}{*}{7} & 7.1 & Loucura e trabalho & 0 & 19 \\
\hline & 7.2 & Loucura no trabalho & 0 & 18 \\
\hline & 7.3 & Loucura do trabalho & 0 & 19 \\
\hline \multirow{3}{*}{8} & 8.1 & Sofrimento mental e trabalho & 0 & 38 \\
\hline & 8.2 & Sofrimento mental no trabalho & 10 & 35 \\
\hline & 8.3 & Sofrimento mental do trabalho & 0 & 38 \\
\hline \multirow{3}{*}{9} & 9.1 & Transtorno psíquico e trabalho & 0 & 2 \\
\hline & 9.2 & Transtorno psíquico no trabalho & 0 & 2 \\
\hline & 9.3 & Transtorno psíquico do trabalho & 0 & 2 \\
\hline \multirow{3}{*}{10} & 10.1 & Estresse mental e trabalho & 0 & 3 \\
\hline & 10.2 & Estresse mental no trabalho & 0 & 3 \\
\hline & 10.3 & Estresse mental do trabalho & 10 & 3 \\
\hline \multicolumn{3}{|l|}{ Total } & 361 & 1064 \\
\hline
\end{tabular}

Fonte: Autor, 2013.

\section{Fase de Cruzamento}

Nesta fase, busca-se realizar uma análise comparativa entre todas as teses e dissertações que passaram pela fase de Refinamento, com o intuito de averiguar a duplicidade de material coletado, isto é, verificar se uma mesma tese ou dissertação foi capturada por mais de um descritor nos dois bancos de dados.

Os procedimentos realizados nessa fase podem ser caracterizados por três etapas distintas e complementares: Cruzamento intradescritor, Cruzamento interdescritor e Cruzamento final. Segue-se a descrição de cada etapa e os respectivos resultados alcançados. 
Quadro 2. Resultados obtidos com a fase de Refinamento

\begin{tabular}{|c|c|c|c|c|c|c|c|c|}
\hline \multicolumn{9}{|c|}{ Fase 2 - Refinamento } \\
\hline \multirow{2}{*}{\multicolumn{3}{|c|}{ Descritores }} & \multicolumn{2}{|c|}{ Capes } & \multicolumn{2}{|c|}{ Bvs-psi } & \multirow{3}{*}{$\begin{array}{l}\begin{array}{c}\text { Total } \\
\text { fase 1 }\end{array} \\
\\
286 \\
\end{array}$} & \multirow{3}{*}{$\begin{array}{r}\text { Total } \\
\text { fase 2 } \\
\\
157 \\
\end{array}$} \\
\hline & & & \multirow{2}{*}{$\begin{array}{c}\text { Fase 1 } \\
144 \\
\end{array}$} & \multirow{2}{*}{$\begin{array}{c}\text { Fase } 2 \\
119 \\
\end{array}$} & \multirow{2}{*}{$\begin{array}{c}\text { Fase } 1 \\
142\end{array}$} & \multirow{2}{*}{$\begin{array}{c}\text { Fase } 2 \\
38 \\
\end{array}$} & & \\
\hline & 1.1 & Saúde mental e trabalho & & & & & & \\
\hline 1 & 1.2 & Saúde mental no trabalho & 13 & 11 & 127 & 37 & 140 & 48 \\
\hline & 1.3 & Saúde mental do trabalho & 144 & 119 & 141 & 39 & 285 & 158 \\
\hline \multirow{3}{*}{2} & 2.1 & Sofrimento psíquico e trabalho & 1 & 1 & 47 & 19 & 48 & 20 \\
\hline & 2.2 & Sofrimento psíquico no trabalho & 18 & 17 & 44 & 18 & 62 & 35 \\
\hline & 2.3 & Sofrimento psíquico do trabalho & 0 & 0 & 46 & 19 & 46 & 19 \\
\hline \multirow{3}{*}{3} & 3.1 & Psicopatologia e trabalho & 0 & 0 & 42 & 2 & 42 & 2 \\
\hline & 3.2 & Psicopatologia no trabalho & 0 & 0 & 41 & 4 & 41 & 4 \\
\hline & 3.3 & Psicopatologia do trabalho & 10 & 2 & 33 & 4 & 43 & 6 \\
\hline \multirow{3}{*}{4} & 4.1 & Psicodinâmica e trabalho & 0 & 0 & 46 & 19 & 46 & 19 \\
\hline & 4.2 & Psicodinâmica no trabalho & 0 & 0 & 46 & 23 & 46 & 23 \\
\hline & 4.3 & Psicodinâmica do trabalho & 10 & 7 & 41 & 21 & 51 & 28 \\
\hline \multirow{3}{*}{5} & 5.1 & Transtorno mental e trabalho & 0 & 0 & 9 & 0 & 9 & 0 \\
\hline & 5.2 & Transtorno mental no trabalho & 0 & 0 & 8 & 0 & 8 & 0 \\
\hline & 5.3 & Transtorno mental do trabalho & 0 & 0 & 9 & 0 & 9 & 0 \\
\hline \multirow{3}{*}{6} & 6.1 & Doença mental e trabalho & 0 & 0 & 21 & 3 & 21 & 3 \\
\hline & 6.2 & Doença mental no trabalho & 1 & 1 & 18 & 3 & 19 & 4 \\
\hline & 6.3 & Doença mental do trabalho & 0 & 0 & 21 & 3 & 21 & 3 \\
\hline \multirow{3}{*}{7} & 7.1 & Loucura e trabalho & 0 & 0 & 19 & 2 & 19 & 2 \\
\hline & 7.2 & Loucura no trabalho & 0 & 0 & 18 & 2 & 18 & 2 \\
\hline & 7.3 & Loucura do trabalho & 0 & 0 & 19 & 2 & 19 & 2 \\
\hline \multirow{3}{*}{8} & 8.1 & Sofrimento mental e trabalho & 0 & 0 & 38 & 21 & 38 & 21 \\
\hline & 8.2 & Sofrimento mental no trabalho & 10 & 5 & 35 & 21 & 45 & 26 \\
\hline & 8.3 & Sofrimento mental do trabalho & 0 & 0 & 38 & 21 & 38 & 21 \\
\hline \multirow{3}{*}{9} & 9.1 & Transtorno psíquico e trabalho & 0 & 0 & 2 & 1 & 2 & 1 \\
\hline & 9.2 & Transtorno psíquico no trabalho & 0 & 0 & 2 & 1 & 2 & 1 \\
\hline & 9.3 & Transtorno psíquico do trabalho & 0 & 0 & 2 & 1 & 2 & 1 \\
\hline \multirow{3}{*}{10} & 10.1 & Estresse mental e trabalho & 0 & 0 & 3 & 3 & 3 & 3 \\
\hline & 10.2 & Estresse mental no trabalho & 0 & 0 & 3 & 3 & 3 & 3 \\
\hline & 10.3 & Estresse mental do trabalho & 10 & 9 & 3 & 3 & 13 & 12 \\
\hline \multicolumn{3}{|c|}{ Total } & 361 & 291 & 1064 & 333 & 1425 & 624 \\
\hline
\end{tabular}

Fonte: Autor, 2013.

\section{Cruzamento intradescritor}

O Cruzamento intradescritor visa realizar a comparação entre todas as teses e dissertações capturadas por cada descritor em suas três variações sintáticas, ou seja, nesse primeiro cruzamento a análise comparativa dá-se no âmbito específico de cada descritor e os resultados são apresentados ainda considerando essa divisão.

Como cada descritor apresenta três construções distintas, e levando-se em consideração a necessidade de tomar uma referência para a comparação, optou-se por tomar a primeira variação como referência. Por exemplo, no descritor 1 - saúde mental e trabalho e suas variações sintáticas: saúde mental no trabalho e saúde mental do trabalho, a comparação é feita cruzando o material coletado com as variações: saúde mental no trabalho e saúde mental do trabalho, em relação à primeira variação: saúde mental e trabalho.

Os resultados quantitativos obtidos com o Cruzamento intradescritor induziram a outro resultado, este referente à configuração das três construções distintas propostas para os descritores de busca no início deste estudo. Estes passaram a assumir uma única formatação em que se aglutinam as variações sintáticas representadas pelos conectivos e, no e do. Tomando-se como exemplo o descritor 2 - sofrimento psíquico e trabalho e suas variações sintáticas, sofrimento psíquico no trabalho 
e sofrimento psíquico do trabalho, com a etapa de Cruzamento intradescritor essas variações são agregadas, resultando na seguinte conformação: descritor 2 - sofrimento psíquico e (no/do) trabalho.

O Quadro 3 ilustra os procedimentos realizados na etapa de Cruzamento intradescritor e apresenta uma comparação entre os resultados obtidos na fase de Refinamento e os resultados alcançados com essa primeira etapa da fase de Cruzamento.

Quadro 3. Resultados obtidos com a etapa de Cruzamento intradescritor da fase de Cruzamento

\begin{tabular}{|c|c|c|c|c|c|c|c|c|c|}
\hline \multicolumn{10}{|c|}{ Fase 3 - Cruzamento / etapa - cruzamento intradescritor } \\
\hline \multirow{2}{*}{\multicolumn{3}{|c|}{ Descritor }} & \multicolumn{2}{|c|}{ Capes } & \multicolumn{2}{|c|}{ Bvs-psi } & \multirow[b]{2}{*}{$\begin{array}{l}\text { Descritores } \\
\text { resultantes }\end{array}$} & \multirow[b]{2}{*}{$\begin{array}{l}\text { Total } \\
\text { fase } 2\end{array}$} & \multirow[b]{2}{*}{$\begin{array}{l}\text { Total } \\
\text { fase } 3\end{array}$} \\
\hline & & & Fase 2 & $\begin{array}{c}\text { Fase } 3 \\
\text { cruzamento }\end{array}$ & Fase 2 & $\begin{array}{c}\text { Fase } 3 \\
\text { cruzamento }\end{array}$ & & & \\
\hline \multirow{3}{*}{1} & 1.1 & $\begin{array}{l}\text { Saúde mental e } \\
\text { trabalho }\end{array}$ & 119 & \multirow{3}{*}{126} & 38 & \multirow{3}{*}{39} & \multirow{3}{*}{$\begin{array}{l}\text { Saúde mental } \\
\text { e (no / do) } \\
\text { trabalho }\end{array}$} & \multirow{3}{*}{363} & \multirow{3}{*}{165} \\
\hline & 1.2 & $\begin{array}{l}\text { Saúde mental no } \\
\text { trabalho }\end{array}$ & 11 & & 37 & & & & \\
\hline & 1.3 & $\begin{array}{l}\text { Saúde mental do } \\
\text { trabalho }\end{array}$ & 119 & & 39 & & & & \\
\hline \multirow{3}{*}{2} & 2.1 & $\begin{array}{l}\text { Sofrimento psíquico e } \\
\text { trabalho }\end{array}$ & 1 & \multirow{3}{*}{18} & 19 & \multirow{3}{*}{20} & \multirow{3}{*}{$\begin{array}{l}\text { Sofrimento } \\
\text { psíquico e (no/ } \\
\text { do) trabalho }\end{array}$} & \multirow{3}{*}{74} & \multirow{3}{*}{38} \\
\hline & 2.2 & $\begin{array}{l}\text { Sofrimento psíquico no } \\
\text { trabalho }\end{array}$ & 17 & & 18 & & & & \\
\hline & 2.3 & $\begin{array}{l}\text { Sofrimento psíquico do } \\
\text { trabalho }\end{array}$ & 0 & & 19 & & & & \\
\hline \multirow{3}{*}{3} & 3.1 & \begin{tabular}{|l|}
$\begin{array}{l}\text { Psicopatologia e } \\
\text { trabalho }\end{array}$ \\
\end{tabular} & 0 & \multirow{3}{*}{2} & 2 & \multirow{3}{*}{4} & \multirow{3}{*}{$\begin{array}{l}\text { Psicopatologia } \\
\text { e (no/do) } \\
\text { trabalho }\end{array}$} & \multirow{3}{*}{12} & \multirow{3}{*}{6} \\
\hline & 3.2 & $\begin{array}{l}\text { Psicopatologia no } \\
\text { trabalho }\end{array}$ & 0 & & 4 & & & & \\
\hline & 3.3 & $\begin{array}{l}\text { Psicopatologia do } \\
\text { trabalho }\end{array}$ & 2 & & 4 & & & & \\
\hline & 4.1 & $\begin{array}{l}\text { Psicodinâmica e } \\
\text { trabalho }\end{array}$ & 0 & \multirow{3}{*}{7} & 19 & \multirow{3}{*}{24} & \multirow{3}{*}{$\begin{array}{l}\text { Psicodinâmica } \\
\text { e (no/do) } \\
\text { trabalho }\end{array}$} & & \\
\hline 4 & 4.2 & $\begin{array}{l}\text { Psicodinâmica no } \\
\text { trabalho }\end{array}$ & 0 & & 23 & & & 70 & 31 \\
\hline & 4.3 & $\begin{array}{l}\text { Psicodinâmica do } \\
\text { trabalho }\end{array}$ & 7 & & 21 & & & & \\
\hline & 5.1 & $\begin{array}{l}\text { Doença mental e } \\
\text { trabalho }\end{array}$ & 0 & & 3 & & & & \\
\hline 5 & 5.2 & \begin{tabular}{|l|}
$\begin{array}{l}\text { Doença mental no } \\
\text { trabalho }\end{array}$ \\
\end{tabular} & 1 & 1 & 3 & 3 & $\begin{array}{l}\text { Doença mental } \\
\text { e (no/do) } \\
\text { trabalho }\end{array}$ & 10 & 4 \\
\hline & 5.3 & $\begin{array}{l}\text { Doença mental do } \\
\text { trabalho }\end{array}$ & 0 & & 3 & & & & \\
\hline & 6.1 & Loucura e trabalho & 0 & & 2 & & & & \\
\hline 6 & 6.2 & Loucura no trabalho & 0 & 0 & 2 & 2 & $\begin{array}{l}\text { Loucura e (no/ } \\
\text { do) trabalho }\end{array}$ & 6 & 2 \\
\hline & 6.3 & Loucura do trabalho & 0 & & 2 & & & & \\
\hline & 7.1 & $\begin{array}{l}\text { Sofrimento mental e } \\
\text { trabalho }\end{array}$ & 0 & & 21 & & & & \\
\hline 7 & 7.2 & $\begin{array}{l}\begin{array}{l}\text { Sofrimento mental no } \\
\text { trabalho }\end{array} \\
\end{array}$ & 5 & 5 & 21 & 21 & $\begin{array}{l}\text { Sofrimento } \\
\text { mental e (no/ } \\
\text { do) trabalho }\end{array}$ & 68 & 26 \\
\hline & 7.3 & $\begin{array}{l}\text { Sofrimento mental do } \\
\text { trabalho }\end{array}$ & 0 & & 21 & & & & \\
\hline & 8.1 & $\begin{array}{l}\text { Transtorno psíquico e } \\
\text { trabalho }\end{array}$ & 0 & & 1 & & & & \\
\hline 8 & 8.2 & $\begin{array}{l}\text { Transtorno psíquico no } \\
\text { trabalho }\end{array}$ & 0 & 0 & 1 & 1 & 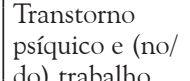 & 3 & 1 \\
\hline & 8.3 & $\begin{array}{l}\text { Transtorno psíquico do } \\
\text { trabalho }\end{array}$ & 0 & & 1 & & & & \\
\hline & 9.1 & $\begin{array}{l}\text { Estresse mental e } \\
\text { trabalho }\end{array}$ & 0 & & 3 & & & & \\
\hline 9 & 9.2 & $\begin{array}{l}\text { Estresse mental no } \\
\text { trabalho }\end{array}$ & 0 & 9 & 3 & 3 & $\begin{array}{l}\text { Estresse mental } \\
\mathrm{e}(\mathrm{no} / \mathrm{do})\end{array}$ & 18 & 12 \\
\hline & 9.3 & $\begin{array}{l}\text { Estresse mental do } \\
\text { trabalho }\end{array}$ & 9 & & 3 & & & & \\
\hline To & & & 291 & 168 & 333 & 117 & & 624 & 285 \\
\hline
\end{tabular}

Fonte: Autor, 2013. 
Ao proceder-se a análise do Quadro 3, é possível perceber a eficiência da primeira etapa da fase de Cruzamento, pois esta elimina mais de $50 \%$ das repetições que comprometiam a qualidade da amostra por falsearem o volume de material coletado.

A amostra que contava com 624 documentos resultantes da fase de Refinamento, passa, ainda na primeira etapa da fase de Cruzamento, a ser composta por 285 documentos, ou seja, menos da metade do material refinado permanece na amostra, o que corresponde a $46 \%$.

É possível observar com clareza a hegemonia do descritor 1 - saúde mental e (no/do) trabalho, que, após mais um tratamento, permanece como aquele que apresenta a maior quantidade de teses e dissertações coletadas nos dois bancos de dados, compondo 165 documentos; correspondendo a $58 \%$ do total de documentos, que é de 285.

\section{Cruzamento interdescritor}

Após os resultados alcançados com a etapa de Cruzamento intradescritor, um novo tratamento é realizado com o mesmo objetivo. Trata-se de mais uma análise comparativa entre todas as teses e dissertações, visando eliminar as repetições que ainda persistem na amostra. No entanto, nessa etapa a comparação dá-se entre os descritores, buscando encontrar material capturado em duplicidade por mais de um descritor de busca.

Quadro 4. Resultados obtidos com a etapa de Cruzamento interdescritor da fase de Cruzamento

\begin{tabular}{|c|c|c|c|c|c|c|c|}
\hline \multicolumn{8}{|c|}{ Fase 3 - cruzamento / etapa - cruzamento interdescritor } \\
\hline & \multirow[b]{2}{*}{ Descritores } & \multicolumn{2}{|c|}{ Capes } & \multicolumn{2}{|c|}{ Bvs-psi } & \multirow{2}{*}{$\begin{array}{c}\text { Total } \\
\text { cruzamento } \\
\text { intra }\end{array}$} & \multirow{2}{*}{$\begin{array}{c}\text { Total } \\
\text { cruzamento } \\
\text { inter }\end{array}$} \\
\hline & & Fase 3 cruzamento & Fase 3 cruzamento & Fase 3 & Fase 3 & & \\
\hline 1 & $\begin{array}{l}\text { Saúde mental } \\
\text { e (no / do) trabalho }\end{array}$ & 126 & 126 & 39 & 39 & 165 & 165 \\
\hline 2 & $\begin{array}{c}\text { Sofrimento } \\
\text { psíquico e (no/ do) } \\
\text { trabalho }\end{array}$ & 18 & 16 & 20 & 12 & 38 & 28 \\
\hline 3 & $\begin{array}{l}\text { Psicopatologia } \\
\text { e (no / do) trabalho }\end{array}$ & 2 & 1 & 4 & 2 & 6 & 3 \\
\hline 4 & $\begin{array}{c}\text { Psicodinâmica } \\
\text { e (no / do) } \\
\text { trabalho }\end{array}$ & 7 & 6 & 24 & 15 & 31 & 21 \\
\hline 5 & $\begin{array}{c}\text { Doença } \\
\text { mental e (no / do) } \\
\text { trabalho }\end{array}$ & 1 & 0 & 3 & 0 & 4 & 0 \\
\hline 6 & $\begin{array}{c}\text { Loucura } \\
\text { e (no / do) trabalho }\end{array}$ & 0 & 0 & 2 & 1 & 2 & 1 \\
\hline 7 & $\begin{array}{c}\text { Sofrimento } \\
\text { mental e (no / do) } \\
\text { trabalho }\end{array}$ & 5 & 4 & 21 & 1 & 26 & 5 \\
\hline 8 & $\begin{array}{c}\text { Transtorno } \\
\text { psíquico e (no / do) } \\
\text { trabalho }\end{array}$ & 0 & 0 & 1 & 1 & 1 & 1 \\
\hline 9 & $\begin{array}{l}\text { Estresse mental } \\
\text { e (no / do) trabalho }\end{array}$ & 9 & 6 & 3 & 0 & 12 & 6 \\
\hline & & 168 & 159 & 117 & 71 & 285 & 230 \\
\hline
\end{tabular}

Fonte: Autor, 2013. 
Considerando a necessidade de estabelecer uma referência para a comparação que caracteriza a etapa de Cruzamento interdescritor, foi tomado o descritor 1 - saúde mental e (no/ do) trabalho para essa função. Essa opção se justifica pela representatividade que esse descritor vem apresentando ao longo das fases anteriores nos dois bancos de dados consultados.

O Quadro 4 apresenta os resultados obtidos com a etapa de Cruzamento interdescritor e traz ainda uma comparação entre os resultados obtidos com a etapa de Cruzamento intra e interdescritor da fase de Cruzamento.

Concluída a etapa de Cruzamento interdescritor, observa-se que a quantidade de documentos passou de 285, provenientes da etapa de Cruzamento intradescritor, para 230. Tem-se a redução de 19\% do material que ainda se apresentava repetido, equivalente a 55 documentos duplicados por terem sido coletados por mais de um descritor.

Essa segunda etapa da fase de Cruzamento também elimina do material o descritor 5 - doença mental e (no/do) trabalho, pois todos os documentos que permaneciam até então relacionados a esse descritor mostraram-se repetidos, anulando sua função para os tratamentos seguintes.

\section{Cruzamento final}

Finalizando a fase de Cruzamento, essa etapa tem como objetivo realizar mais uma análise comparativa visando eliminar repetições de documentos na amostra num último nível possível. A comparação nessa etapa dá-se entre todas as teses e dissertações capturadas pelos descritores de busca no banco da CAPES e da BVS-Psi. O banco da CAPES é tomado como referência, ou seja, são comparados os documentos coletados na BVS-Psi em relação aos documentos coletados no banco da CAPES. Com essa fase fica assegurada a autenticidade da amostra, pois são eliminadas todas as repetições.

Quadro 5. Resultados obtidos com a etapa de Cruzamento final da fase de Cruzamento

\begin{tabular}{|c|c|c|c|c|c|c|c|}
\hline \multicolumn{8}{|c|}{ Fase 3 - Cruzamento / etapa - cruzamento final } \\
\hline & & \multicolumn{2}{|c|}{ Capes } & \multicolumn{2}{|c|}{ Bvs-psi } & \multirow[b]{2}{*}{$\begin{array}{l}\text { Total } \\
\text { cruzamento } \\
\text { inter- } \\
\text { descritor }\end{array}$} & \multirow[b]{2}{*}{$\begin{array}{l}\text { Total } \\
\text { cruzamento } \\
\text { final }\end{array}$} \\
\hline Descritores & & $\begin{array}{c}\text { Fase } 3 \\
\text { cruzamento } \\
\text { inter- } \\
\text { descritor }\end{array}$ & $\begin{array}{c}\text { Fase } 3 \\
\text { cruzamento } \\
\text { final }\end{array}$ & $\begin{array}{c}\text { Fase } 3 \\
\text { cruzamento } \\
\text { inter- } \\
\text { descritor }\end{array}$ & $\begin{array}{l}\text { Fase } 3 \\
\text { cruzamento } \\
\quad \text { final }\end{array}$ & & \\
\hline 1 & $\begin{array}{l}\text { Saúde mental e (no / } \\
\text { do) trabalho }\end{array}$ & 126 & 126 & 39 & 28 & 165 & 154 \\
\hline 2 & $\begin{array}{l}\text { Sofrimento psíquico } \\
\text { e (no / do) trabalho }\end{array}$ & 16 & 16 & 12 & 12 & 28 & 28 \\
\hline 3 & $\begin{array}{l}\text { Psicopatologia } \\
\text { e (no / do) } \\
\text { trabalho }\end{array}$ & 1 & 1 & 2 & 2 & 3 & 3 \\
\hline 4 & $\begin{array}{c}\text { Psicodinâmica } \\
\text { e (no / do) trabalho } \\
\end{array}$ & 6 & 6 & 15 & 15 & 21 & 21 \\
\hline 5 & $\begin{array}{c}\text { Loucura } \\
\text { e (no / do) trabalho }\end{array}$ & 0 & 0 & 1 & 1 & 1 & 1 \\
\hline 6 & $\begin{array}{c}\text { Sofrimento } \\
\text { mental e (no / do) } \\
\text { trabalho }\end{array}$ & 4 & 4 & 1 & 1 & 5 & 5 \\
\hline 7 & \begin{tabular}{|c|} 
Transtorno \\
psíquico e (no / do) \\
trabalho
\end{tabular} & 0 & 0 & 1 & 1 & 1 & 1 \\
\hline 8 & $\begin{array}{c}\text { Estresse mental } \\
\text { e (no / do) trabalho }\end{array}$ & 6 & 6 & 0 & 0 & 6 & 6 \\
\hline \multicolumn{2}{|l|}{ Total } & 159 & 159 & 71 & 60 & 230 & 219 \\
\hline
\end{tabular}

Fonte: Autor, 2013. 


\section{Resultados e discussão}

\section{Fase de Descrição}

A fase de Descrição apresenta os resultados alcançados por esse estudo, ou seja, traz um panorama da área da Saúde mental e trabalho na produção acadêmica brasileira no contexto da pós-graduação.

Portanto, descreve-se minuciosamente toda amostra quanto ao tipo de trabalho desenvolvido no contexto acadêmico, sendo tese ou dissertação, referente à frequência ano a ano da produção dos documentos: série histórica; quanto à área do conhecimento a qual cada documento se vincula; quanto à disposição geográfica da produção por unidade da federação, e ainda, quanto à procedência institucional de cada tese e dissertação produzida.

\section{Tipo de documento}

A identificação do tipo de documento (tese ou dissertação) permite reconhecer o nível de formação, mestrado ou doutorado, em que a produção na área da Saúde mental e trabalho se encontra, no âmbito da pós-graduação brasileira.

\section{Gráfico 1. Resultados obtidos com a fase de Descrição quanto ao tipo do documento}

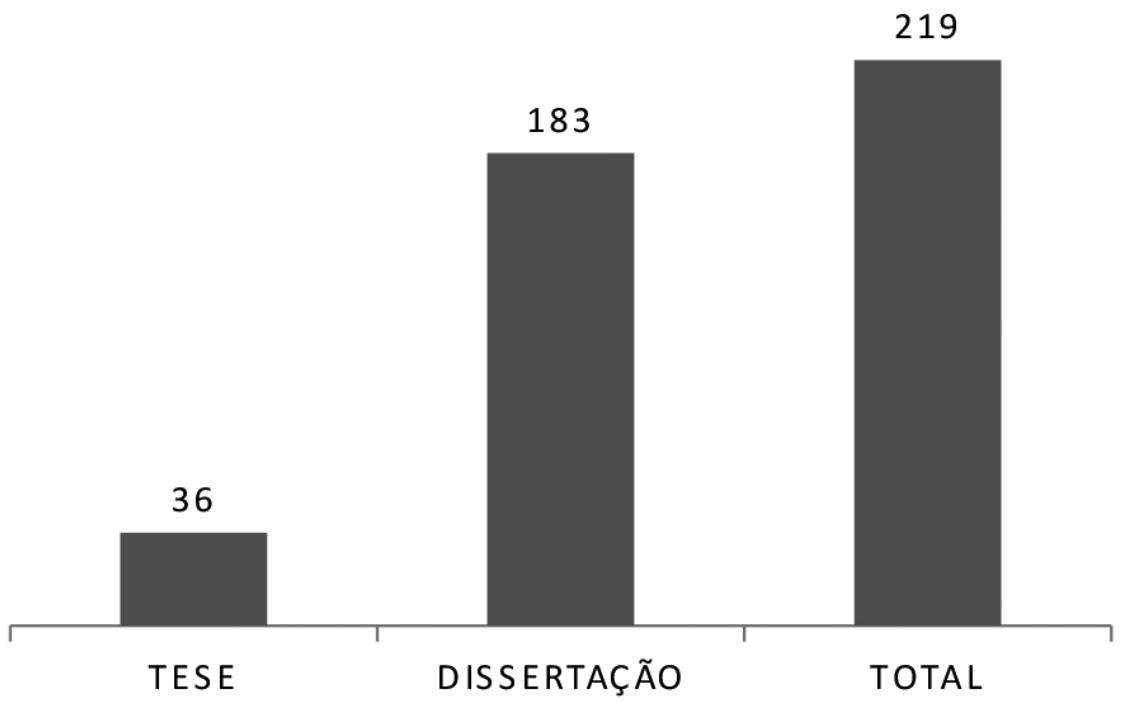

Fonte: Autor, 2013.

A quantidade de documentos apresentada pelo Gráfico 1 corresponde a 16\% de teses e 84\% de dissertações, indicando que a produção na área de Saúde mental e trabalho no Brasil vinculase, predominantemente, ao nível de mestrado.

Pode-se observar ainda uma correspondência com os dados gerais da pós-graduação brasileira, onde verifica-se que $65 \%$ são cursos de mestrado/mestrado profissional e 35\% são cursos de doutorado (Coordenação de Aperfeiçoamento de Pessoal de Nível Superior, 2010).

O cruzamento dessas informações indica que o desenvolvimento da área de Saúde mental e trabalho acompanha o desenvolvimento da própria oferta de cursos de formação em nível de pós-graduação no Brasil. 


\section{Série histórica}

Observar o contexto histórico da produção acadêmica de uma área de conhecimento pode ampliar as possibilidades de interpretação dos dados. Aqui se apresenta a frequência anual da produção das teses e dissertações.

Gráfico 2. Resultados obtidos com a fase de Descrição quanto à série histórica

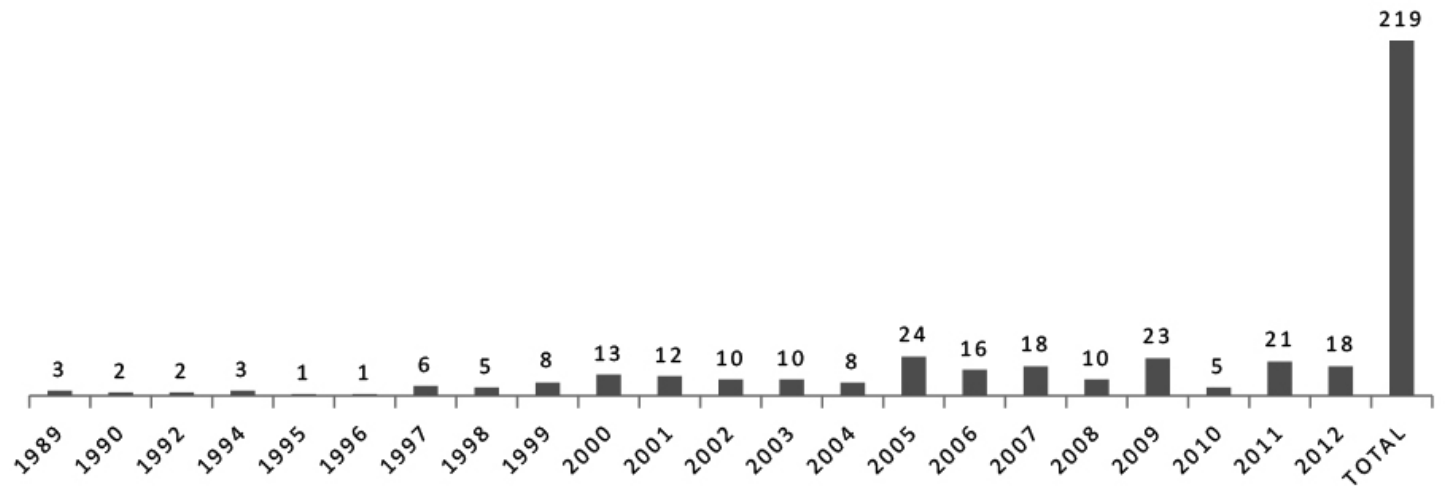

Fonte: Autor, 2013.

Ao descrever-se a série histórica da área da Saúde mental e trabalho no Brasil, dois aspectos chamam atenção: o primeiro diz respeito ao período em que aparecem os primeiros documentos, pois, nesse mesmo período, final dos anos de 1980, verifica-se uma produção crescente de pesquisas voltadas para investigação dos impactos causados no mundo do trabalho pelos processos de reestruturação produtiva no Brasil (Tumolo, 2001).

A articulação entre essas informações parece indicar uma relação diretamente proporcional, isto é, à medida que as transformações no mundo do trabalho se efetivam atraindo o interesse de pesquisadores, a área de Saúde mental e trabalho apresenta suas primeiras produções na pósgraduação brasileira. É possível, portanto, estabelecer uma relação entre o impacto causado pelas mudanças no mundo do trabalho, resultado dos processos de reestruturação produtiva no Brasil, e a saúde mental dos trabalhadores.

O segundo aspecto relevante em relação à série histórica está relacionado ao volume concentrado nos últimos doze anos. De 1989 a 1999 encontram-se 12\% do total de documentos, sendo a maior parte, $88 \%$, produzidos entre os anos de 2000 a 2012. Essa concentração no período compreendido entre os anos de 2000 a 2012 acompanha os dados gerais da pós-graduação brasileira, onde praticamente se duplica a oferta de cursos a partir do ano 2000, com um crescimento de $48 \%$ dessa oferta (CAPES, 2010).

Parece ainda relevante atentar para uma possível relação entre o volume de produção concentrada entre os anos de 2000 a 2012 e a conjuntura política brasileira no mesmo período.

\section{Área do conhecimento}

Com essa descrição, propõe-se a identificação das áreas do conhecimento às quais estão vinculadas a produção acadêmica na área de Saúde mental e trabalho, e qual dentre essas áreas apresenta a produção mais significativa. 
Gráfico 3. Resultados obtidos a partir da fase de Descrição quanto à área do conhecimento

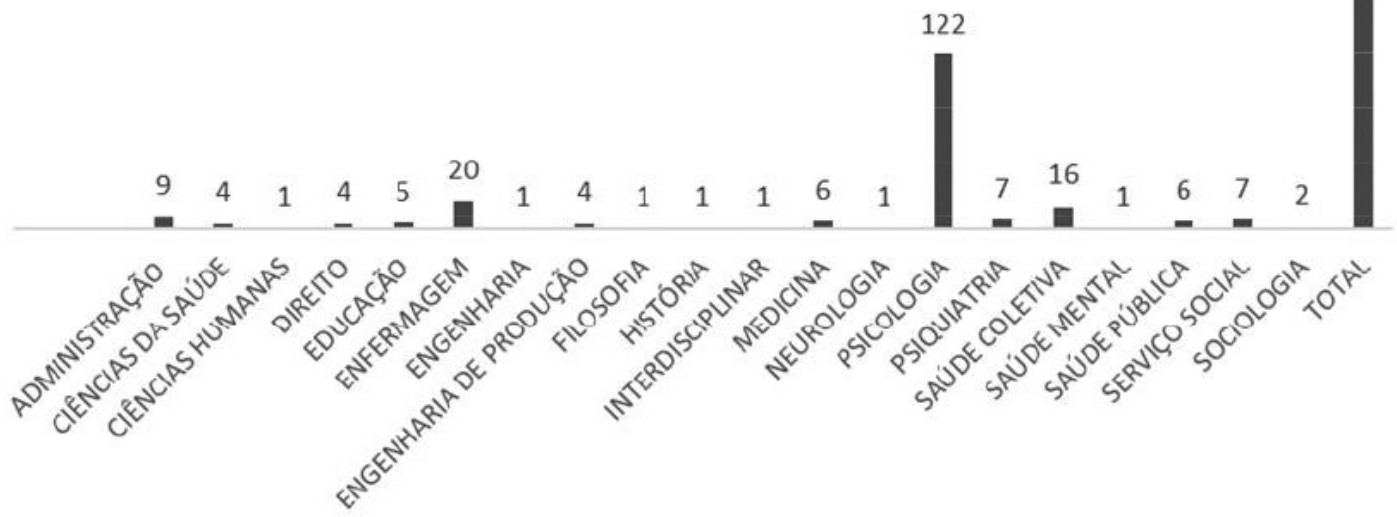

Fonte: Autor, 2013.

O Gráfico 3 apresenta 20 áreas do conhecimento nas quais estão vinculadas as 219 teses e dissertações provenientes dos dois bancos de dados consultados. Dessas 20 áreas, observa-se a hegemonia da Psicologia, que apresenta resultado correspondente a 56\% da produção coletada. Destaca-se o conjunto da grande área de Saúde, nesta amostra representada pelas áreas identificadas como Ciências da Saúde, Enfermagem, Medicina, Neurologia, Psiquiatria, Saúde Coletiva, Saúde Mental e Saúde Pública, que juntas somam 61 documentos, correspondente a $28 \%$ do total. Não menos importante é destacar a vinculação com outras áreas, como Administração, Direito, Engenharia ou Sociologia. Essa diversidade parece indicar que o interesse pelo estudo da relação entre Saúde mental e trabalho assume uma característica multidisciplinar.

Apesar da indicação de que se trata de uma área de interesse multidisciplinar, pois existem trabalhos vinculados à áreas como Direito, Engenharia, Educação, Filosofia, História e Serviço Social, a constatação de que a quase totalidade $(84 \%)$ da produção da área de Saúde mental e trabalho é identificada com as áreas da Psicologia e Saúde, apontam para um direcionamento paradigmático ou epistemológico.

\section{Disposição geográfica}

Gráfico 4. Resultados alcançados com a fase de Descrição quanto à disposição geográfica

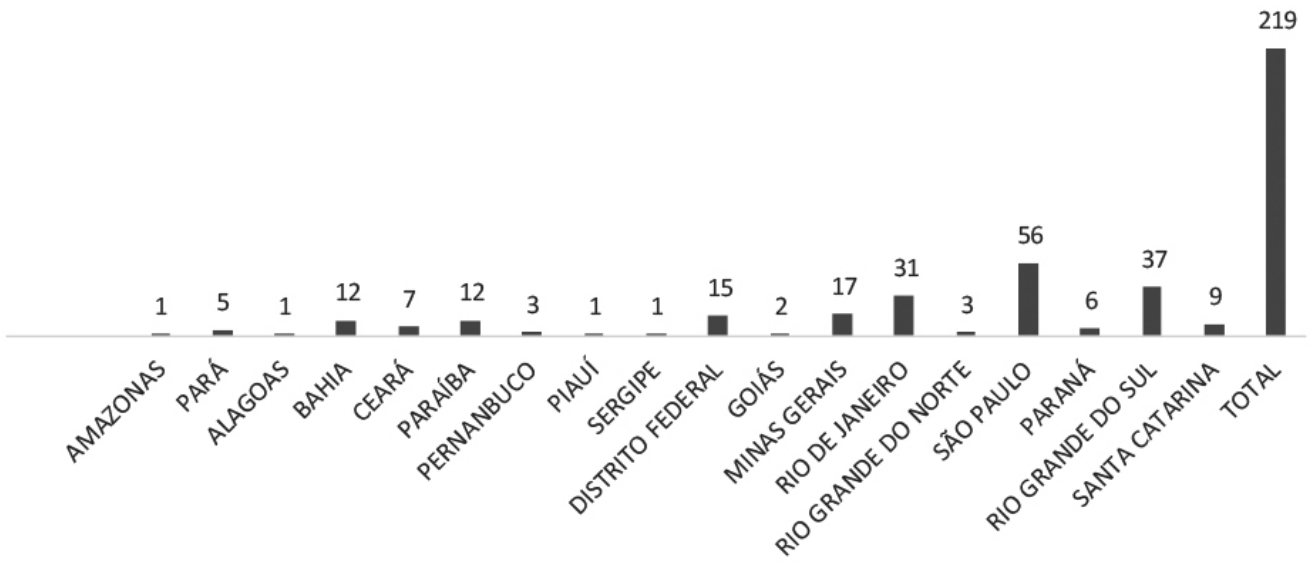

Fonte: Autor, 2013. 
A disposição geográfica a partir das unidades da federação compreende um mapeamento dos polos de produção no nível da pós-graduação na área estudada.

O Gráfico 4 apresenta a disposição geográfica por estado, de onde provêm as 219 teses e dissertações localizadas.

Localizar a origem da produção acerca da área de Saúde mental e trabalho possibilita o reconhecimento da dimensão que esta área vem alcançando em território nacional, tendo em vista a distribuição geográfica atingida. Quando é analisado de onde provêm as teses e dissertações, percebe-se uma disposição geográfica abrangente onde existe produção nas cinco regiões do país e em 18 das 27 unidades da federação. Além desse panorama, é possível também identificar as regiões que apresentam maior produção na área.

Assim, tem-se que o estado de São Paulo responde por 30\% do total de teses e dissertações produzidas. Somando os resultados dos estados que compõem a região Sudeste do país, observa-se que esta responde por $46 \%$ do total da produção acadêmica na área de Saúde mental e trabalho no Brasil.

Parece possível avançar na compreensão desses dados ao se estabelecer uma relação entre a concentração da produção acadêmica da área de Saúde mental e trabalho e a distribuição assimétrica da própria oferta de cursos de pós-graduação no Brasil, onde é observada uma concentração de 50\% dos cursos na região Sudeste (CAPES, 2010).

Quando se constata essa relação de proporcionalidade e também considerando a ampla distribuição dos estudos no território brasileiro, pode-se afirmar que esta área tem alcançado uma abrangência significativa e que o interesse de pesquisadores ultrapassa os polos tradicionais de pesquisa.

\section{Procedência institucional}

A descrição da procedência institucional de todas as teses e dissertações que compõem a amostra amplia a localização dos documentos, indo além da identificação geográfica e apontando quais Instituições de Ensino Superior (IES) no país estão produzindo na área de Saúde mental e trabalho.

Gráfico 5. Resultados alcançados com a fase de Descrição quanto à procedência institucional.

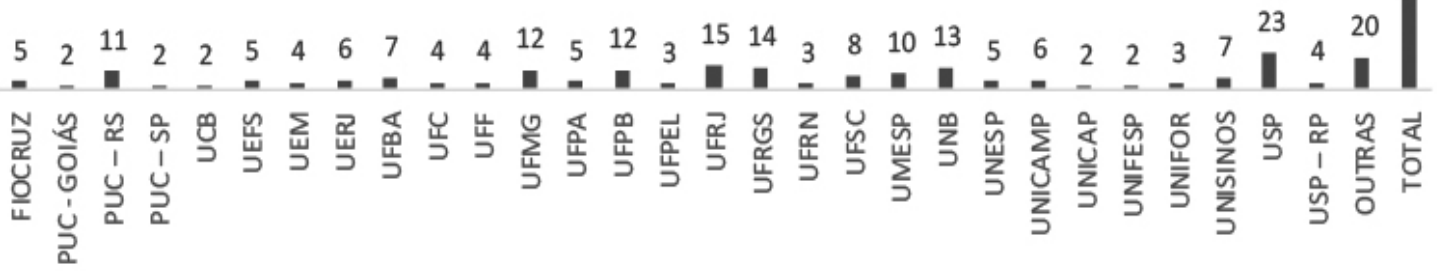

Fonte: Autor, 2013.

Avançando na localização da origem das teses e dissertações, identifica-se a procedência institucional desses documentos. Com essa informação, avança-se também na compreensão da abrangência e penetração que a área de Saúde mental e trabalho tem alcançado no contexto acadêmico no Brasil. 
Seguindo nessa direção, ao atentar-se à procedência institucional das teses e dissertações, localizam-se 49 IES. Se ao apontar a disposição geográfica tornou-se possível perceber a abrangência que a área tem alcançado na localização das instituições provenientes, essa abrangência é ainda mais significativa, pois, como apontado acima, são diversas as instituições que apresentam produção na área, não configurando polos de concentração de produção do conhecimento em nível institucional.

Entre as 49 instituições, 61\% são públicas e 39\% são instituições privadas. As instituições públicas respondem por $77 \%$ do total de documentos e as privadas apresentam $23 \%$ da produção na área, o que possibilita afirmar que a área de Saúde mental e trabalho tem sido estudada predominantemente em instituições públicas.

É possível ratificar essa informação observando-se as cinco instituições que apresentam maior produção: USP, com 10\% do total de teses e dissertações encontradas, UFRJ, UFRGS e UNB, com 6\% cada, e a UFMG, com 5\%.

\section{Considerações finais}

Os resultados alcançados apresentam um panorama da área de Saúde mental e trabalho a partir do qual é possível observar que a produção acadêmica no contexto da pós-graduação vincula-se, eminentemente, ao nível de mestrado, pois $84 \%$ a amostra é composta por dissertações e apenas $16 \%$ por teses.

No final dos anos de 1980 surgiram os primeiros documentos, mais precisamente em 1989. A partir do ano 2000, observa-se um crescimento considerável da produção; $88 \%$ do total de documentos presentes na amostra encontram-se nesse período.

Predominam estudos ligados à Psicologia, pois $56 \%$ das teses e dissertações localizadas estão ligadas à essa área do conhecimento. A região Sudeste concentra $46 \%$ do total da produção, e o estado de São Paulo responde por 30\% do total, indicando uma concentração de estudos nessa região do país. Identifica-se ainda 49 IES que apresentam produção na área, sendo a USP, UFRJ, UFRGS, UNB e a UFMG as que mais produzem.

A área de Saúde mental e trabalho emergiu no esteio do campo da Saúde do trabalhador no Brasil e de sua inserção no contexto acadêmico da pós-graduação. Enquanto área específica é resultado do processo socio-histórico que possibilitou "o início de um novo diálogo" entre a Psicologia e a Saúde do trabalhador na década de 1980 (Sato, Lacaz, Bernardo, 2006, p. 283). Não por acaso, Psicologia é a ciência que mais tem se ocupado com os estudos na área de Saúde mental e trabalho. O pioneirismo de São Paulo (Lacaz, 1996; 1997) no desenvolvimento do campo da Saúde do trabalhador no país parece legitimar a concentração descrita de 30\% do total de produção da área da Saúde mental e trabalho nesse estado.

Destaca-se ainda o papel preponderante das instituições públicas no desenvolvimento de pesquisas na área, o que parece indicar um compromisso ético e político dessas instituições em responder aos problemas enfrentados pela sociedade, demandando investigação científica.

\section{Referências}

Amarante, P. (2007). Saúde mental e atenção psicossocial. Rio de Janeiro: Fiocruz.

Antunes, R. (Org.). (2004). A dialética do trabalho: escritos de Marx e Engels. São Paulo: Expressão Popular.

Antunes, R., \& Silva, M. A. M. (Orgs.). (2010). O avesso do trabalho (2a ed.). São Paulo: Expressão Popular.

Antunes, R. (2011). Trabalho e estranhamento. In R. Antunes, R., Adeus ao trabalho? Ensaio sobre as metamorfoses e a centralidade do mundo do trabalho (15a ed.) (pp. 142-156). São Paulo: Cortez. 
Araújo, M. A. (2011). Revisão de abordagens teórico-metodológicas sobre saúde mental e trabalho. In C. MinayoGomez, J. M. H. Machado \& P. G. L. Pena. (Orgs.), Saúde do trabalhador na sociedade brasileira contemporânea (pp. 325-343). Rio de Janeiro: Fiocruz.

Arendt, H. (2007). A condição humana (10a ed.). Rio de Janeiro: Forense Universitária.

Bardin, L. (2002). Análise de conteúdo. Lisboa: Portugal: Edições 70.

Borsoi, I. C. F. (2007). Da relação entre trabalho e saúde à relação entre trabalho e saúde mental. Revista Psicologia $\mathscr{E}$ Sociedade, 19(Edição especial 1), 103-111. Recuperado de http://www.scielo.br/pdf/psoc/v19nspe/v19nspea14. pdf

Coordenação de Aperfeiçoamento de Pessoal de Nível Superior. (2010). Plano Nacional de Pós-graduação: PNPG 2011-2020 / Coordenação de aperfeiçoamento de Pessoal de Nível Superior. Recuperado de http://www.capes. gov.br/sobre-a-capes/plano-nacional-de-pos-graduacao/pnpg-2011-2020

Clot, Y. (2007). A função psicológica do trabalho. Petrópolis: Vozes.

Codo, W. (Org.). (2004). Psicopatologia do trabalho. In CODO, W. Codo, O trabalho enlouquece? Um encontro entre a clínica e o trabalho (pp. 11-22). Petrópolis: Vozes.

Codo, W., Soratto, L., \& Vasques-Meneses, I. (2004). Saúde mental e trabalho. In J. C. Zanelli, J. E. Borges-Andrade, \& A. V. B. Bastos (Orgs.), Psicologia, organizações e trabalho no Brasil (pp. 276-299). Porto Alegre: Artmed.

Delgalarrondo, P. (2008). Psicopatologia e semiologia dos transtornos mentais (2a ed.). Porto Alegre: Artmed.

Flick, U. (2009). Introdução à pesquisa qualitativa (3a ed.). Porto Alegre: Artmed.

Frias Junior, C. A. S. (1999). A saúde do trabalhador no Maranhão: uma visão atual e proposta de atuação (Dissertação de Mestrado). Escola Nacional de Saúde Pública, Fundação Oswaldo Cruz, Rio de Janeiro.

Glima, D. M. R. \& Rocha, L. E. (Orgs.). (2010). Saúde mental no trabalho: da teoria à prática. São Paulo: Roca.

Jacques, M. G. C. (2003). Abordagens teórico-metodológicas em saúde/doença mental \& trabalho. Psicologia $\mathscr{E}$ Sociedade, 15(1), 97-116. Recuperado de http://www.scielo.br/pdf/psoc/v15n1/v15n1a06.pdf

Jacques, M. G. C, \& Codo, W. (Orgs.). (2002). Saúde mental \& trabalho: leituras (2a ed.). Petrópolis: Vozes.

Lacaz, F. A. C. (1996). Saúde do trabalhador: um estudo sobre as formações discursivas da academia, dos serviços e do movimento sindical (Tese de doutorado). Faculdade de Ciências Médicas, Universidade Estadual de Campinas, Campinas.

Lacaz, F. A. C. (1997). Saúde dos trabalhadores: Cenários e desafios. Cadernos de Saúde Pública, 13 (2), 7-19. Recuperado de http://www.scielo.br/pdf/csp/v13s2/1360.pdf

Lacaz, F. A. C. (2007). O campo Saúde do trabalhador: resgatando conhecimento e práticas sobre as relações trabalhosaúde. Cadernos de Saúde Pública, 23(4), 757-766. Recuperado de http://www.scielosp.org/pdf/csp/v23n4/02.pdf

Lima, M. E. A. (Org.). (2006). Escritos de Louis Le Guillant: da ergoterapia à psicopatologia do trabalho. Petrópolis, RJ: Vozes.

Lima, M. E. A. (2013). Saúde mental e trabalho: limites, desafios, obstáculos e perspectivas. Cadernos de Psicologia Social do Trabalho, 16(1), 91-98. doi: http://dx.doi.org/10.11606/issn.1981-0490.v16ispe1p91-98

Lukács, G. (2012). Para uma ontologia do ser social I. São Paulo, SP: Boitempo.

Mendes, R. \& Dias, E. C. (1991) Da medicina do trabalho à saúde do trabalhador. Revista de Saúde Pública, 25(5), 341-349.

Minayo-Gomez, C. (2011). Campo da saúde do trabalhador: trajetória, configuração e transformações. In C. MinayoGomez, J. M. H. Machado \& P. G. L. Pena. (Orgs.), Saúde do trabalhador na sociedade brasileira contemporânea (pp. 23-34). Rio de Janeiro, RJ: Fiocruz.

Minayo-Gomez, C., \& Thedim-Costa, S. M. F. T. (1997). A construção do campo da saúde do trabalhador: percursos e dilemas. Cadernos de Saúde Pública, 13(2), 21-32.

Navarro, V. L., \& Padilha, V. (Orgs.). (2009). Retratos do trabalho no Brasil. Uberlândia, MG: Edufu.

Sato, L., Lacaz. F. A. C., \& Bernardo, M. H. (2006). Psicologia e saúde do trabalhador: práticas e investigações na saúde pública de São Paulo. Estudos de Psicologia, 11(3), 281-288.

Sato, L. \& Bernardo, M. H. (2005). Saúde mental e trabalho: os problemas que persistem. Ciência e Saúde Coletiva, 10(4), 869-878.

Seligmann-Silva, E. (2006). Psicopatologia do trabalho. In Anais do 2º Congresso Internacional sobre saúde mental no trabalho (p. 64). Goiânia, GO. 
Seligmann-Silva, E. (2011). Desgaste mental e trabalho. São Paulo, SP: Cortez.

Sennett, R. (2003). A corrosão do caráter (7a ed.). Rio de Janeiro, RJ: Record.

Tumolo, P. S. (2001). Reestruturação produtiva no Brasil: um balanço crítico introdutório da produção bibliográfica. Educação E̊ Sociedade, 22(77), 71-99. Recuperado de: http://www.scielo.br/pdf/es/v22n77/7046.pdf

Vieira, C. E. C., Barros, V. A., \& Lima, F. P. A. (2007). Uma abordagem da Psicologia do Trabalho, na presença do trabalho. Psicologia em revista, 13(1), 155-168. Recuperado de http://periodicos.pucminas.br/index.php/ psicologiaemrevista/article/view/266/275

\section{Endereço para correspondência}

adeliasouto@hotmail.com,juliusbastos@yahoo.com.br
Recebido em: 13/05/2014

Revisado em: 09/01/2015

Aprovado em: 19/02/2015 